Rev. Elet. em Gestão, Educação e Tecnologia Ambiental (e-ISSN: 2236-1170)

\title{
MERCADO INTERNACIONAL DE CARNE BOVINA BRASILEIRA: UMA ANÁLISE DOS ÍNDICES DE CONCENTRAÇÃO DAS EXPORTAÇÕES DE 2000 A 2011
}

\section{INTERNATIONAL MARKET FOR BRAZILIAN BEEF: AN ANALYSIS OF THE CONCENTRATION INDICES OF EXPORTS FROM 2000 TO 2011}

\author{
Eduardo Rodrigues Sanguinet ${ }^{1}$, Rodrigo Klein Lorenzoni ${ }^{2}$, Tatiane Pelegrini ${ }^{3}$, Andrea Cristina Dörr ${ }^{4}$, \\ Ana Paula Burin Fruet ${ }^{5}$, Ana Carolina Kohlrausch Klinger ${ }^{6}$
}

\author{
${ }^{1}$ Universidade Federal de Santa Maria (UFSM) - Acadêmico de Ciências Econômicas. E-mail: \\ eduardorodrigues43@gmail.com \\ ${ }^{2}$ UFSM - Acadêmico de Ciências Econômicas. E-mail: lorenzoni.rodrigo@gmail.com \\ ${ }^{3}$ UFSM - Acadêmica de Ciências Econômicas. E-mail: tatikpelegrini@gmail.com \\ ${ }^{4}$ UFSM - Profa. Adjunto do Departamento de Ciências Econômicas: andreadoerr@yahoo.com.br \\ ${ }^{5}$ UFSM - Mestranda em Mestrado em Ciência e Tecnologia dos Alimentos. E-mail: ap_burin@hotmail.com \\ ${ }^{6}$ UFSM - Acadêmica do Programa para Formação de Professores. E-mail: anaklinger@zootecnista.com.br
}

http://dx.doi.org/10.5902/223611708789

\section{RESUMO}

O estudo avaliou o comércio exportador de carne bovina brasileira e com essa finalidade foi realizada uma análise setorial a fim de diagnosticar os fatores que fazem do Brasil um dos maiores exportadores do produto. Averiguaramse os índices de concentração do mercado consumidor e, concomitantemente, mensura-se a evolução do volume de importação dos 10 maiores compradores (a partir de dados da ABIEC) da carne bovina brasileira no período de 2000 a 2011. Verificou-se que o Brasil tem um potencial para a pecuária devido às vantagens comparativas como abundância de terras e condições climáticas favoráveis e que houve grandes investimentos internos para o setor. Tal fato confirma o aumento do volume de carne bovina brasileira exportada nos últimos anos. Pelo estudo dos índices de concentração, constatou-se que no período de análise, poucos países participaram de forma relevante nas relações comerciais de carne bovina proveniente do Brasil. Conclui-se que há flutuações nos volumes que cada país importa ano a ano, no entanto o grupo dos países de maior significância para as exportações de carne bovina brasileira permanecem constantes e representaram 64\% do total exportado em 2011.

Palavras-chave: exportação, carne, concentração

\begin{abstract}
The study evaluated the export trade of Brazilian beef and to this end we conducted a sectoral analysis to diagnose the factors that make Brazil a major exporter of the product. Ascertained the indexes of market concentration and consumer concurrently measures the evolution of the volume of imports of the 10 largest buyers (from data ABIEC) Brazilian beef in the period from 2000 to 2011. It was found that Brazil has a potential for livestock due to comparative advantages such as abundant land and favorable climatic conditions and that there were major inward investment to the sector. This fact confirms the increasing volume of Brazilian beef exported in recent years. By studying the levels of concentration, it was found that the period of analysis, few countries participated materially in trade of beef from Brazil. We conclude that there are fluctuations in the volumes that each country imports every year, however the group of countries with the highest significance for Brazilian beef exports remain constant and represented $64 \%$ of total exports in 2011.
\end{abstract}

Keywords: export, beef, concentration 
Rev. Elet. em Gestão, Educação e Tecnologia Ambiental (e-ISSN: 2236-1170)

\section{INTRODUÇÃO}

O Brasil apresenta-se no setor de carne bovina como um dos grandes produtores e comerciantes do produto em nível mundial. Com base nos dados da Associação Brasileira das Indústrias Exportadoras de Carne (ABIEC) constata-se o grande volume exportado a cada ano pelo país. O cenário internacional favorável às exportações brasileiras de carne bovina contribuiu para aumentar a parcela de mercado do país no mercado internacional, confirmando assim a importância da produção nacional do referido bem.

O país conseguiu aumentar o volume e as receitas de suas exportações e diversificar os países compradores. O país exportava para 107 países em 2000 e passou a atender 153 países em 2006. O aumento das vendas externas deveu-se ao trabalho dos frigoríficos na padronização do produto entregue e no cumprimento dos prazos, à ampliação de parcerias para distribuição da carne no exterior e aos programas de divulgação da carne brasileira em feiras internacionais (PEROBELLI, 2007). Outros fatores como regulação da produção, investimentos em tecnologia e queda da produção por parte de outros países, colaboraram fortemente para o aumento das exportações brasileiras.

A carne bovina brasileira é exportada para mais de 120 países, porém, o Brasil mantem relações comerciais mais significativas, em termos de volume vendido, para uma gama pequena de países que são responsáveis por um percentual muito alto do montante total vendido.

No estudo da economia industrial, o uso dos índices de concentração mostra a forma como uma indústria distribui-se em um dado mercado. Para o caso deste estudo, será identificado de forma descritiva como os países participam do mercado consumidor da carne bovina produzida no Brasil. A mensuração da concentração fornece elementos empíricos que permitem avaliar a situação de competição em um mercado e serve também para comparações intertemporais que permitem examinar a dinâmica do mercado sob o ponto de vista da oferta (KON, 1994).

Este trabalho objetiva mensurar a variação dos índices de concentração e de evolução das exportações brasileiras de carne bovina no período compreendido de 2000 a 2011 a fim de verificar a dinâmica do mercado comprador do produto em questão ao longo da análise temporal. Propõe-se analisar o setor pecuário para a carne bovina e explorar de forma quantitativa e descritiva a realidade do mercado consumidor de carne bovina brasileira, avaliando a estabilidade do mercado quanto às relações comerciais e o impacto das decisões individuais de cada país relativas ao volume importado em cada período e, se as variações deste impactaram significativamente no total de exportações brasileiras.

\section{METODOLOGIA}

O presente estudo é de natureza pura e consiste-se de um estudo descritivo-explicativo, onde se pretende estabelecer relações entre dados e identificar os fatores que determinam ou que contribuem para a variação do volume de carne bovina brasileira exportada. Os dados utilizados na análise são secundários e provenientes da Associação Brasileira das Indústrias Exportadoras de Carne (ABIEC) e referentes às exportações totais de carne brasileira no período compreendido entre 2000 e 2011. Com a finalidade de analisar a evolução das exportações e a 


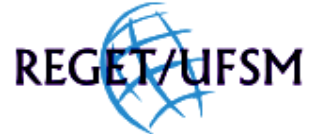

SANGUINET et all , v(11), no 11, p. 2389-2398, JUN, 2013.

Rev. Elet. em Gestão, Educação e Tecnologia Ambiental (e-ISSN: 2236-1170)

concentração em termos de participação de cada país de destino da carne brasileira, também foram utilizadas as informações do volume, em toneladas, exportado para uma amostra de 10 países, que são os maiores importadores de carne bovina brasileira em $2011^{1}$. Para alcançar o objetivo do trabalho, apresenta-se a seguir a concentração das exportações brasileiras segundo a Razão de Concentração (CR).

Hall \& Tideman (1967) e Hannah \& Kay (1977) apresentam o índice de razão de concentração (CR), um indicador que parte do princípio de que as medidas de concentração devem tomar como base as parcelas de mercado de cada firma e considera a concentração uma função da desigualdade das parcelas de mercado e do número de firmas.

No presente estudo, o índice representará as parcelas de importação de cada destinatário estrangeiro das carnes brasileiras. $O$ índice de razão de concentração (CR) é então definido como

$$
\boldsymbol{C R}=\sum_{i=1}^{n} \boldsymbol{P i}
$$

em que $P i$ é a parcela de mercado da i-ésima empresa com $i=(1, \ldots, n)$ ordenado de maneira decrescente onde $n$ é o número total de empresas. $O$ índice varia de 0 (zero) a 100. Quanto mais próximo estiver de 100, mais alta é a concentração nas vendas externas de carne bovina brasileira.

A limitação apresentada por esse índice é que se trata apenas de um ponto na curva de concentração cumulativa. Assim, existe perda de informação na avaliação da concentração por intermédio desse procedimento (CURRY \& GEORGE, 1983).

\section{RESULTADOS E DISCUSSÕES}

O Brasil apresenta características justificáveis para que seja um grande exportador de carne. É o quinto maior país do mundo em território, com 8,5 milhões de $\mathrm{km}^{2}$ de extensão, com cerca de $20 \%$ da sua área (174 milhões de hectares) ocupada por pastagens. A maior parte do rebanho de 209 milhões de cabeças é criada a pasto fazendo com que as chuvas interfiram diretamente na qualidade das pastagens e, portanto, na oferta e preço do gado de região para região. Apesar de ser um país predominantemente tropical, possui uma grande variabilidade climática, refletindo nos regimes pluviométricos e consequentemente nos sistemas de produção pecuários.

Segundo a Associação Brasileira das Indústrias Exportadoras de Carne (ABIEC, 2012) a diversificação de produtos pecuários se deve a grande variedade de sistemas produtivos, tornando o Brasil um país que pode atender qualquer mercado no mundo, sejam nichos específicos, com carnes mais nobres até cortes de menor valor, sejam mais magras ou com maior teor de gordura, sob qualquer demanda de volume. A tecnologia aplicada à pecuária aliada ao desenvolvimento de pesquisa nacional e de técnicas específicas aos sistemas produtivos contribui para que se impulsionem os índices de produtividade dos animais.

\footnotetext{
${ }^{1}$ Os dados são provenientes do ranking da ABIEC dos países que importam carne bovina brasileira (todos os tipos de carne bovina são incluídos).
} 
REGESATFS

SANGUINET et all , v(11), no 11, p. 2389-2398, JUN, 2013.

Rev. Elet. em Gestão, Educação e Tecnologia Ambiental (e-ISSN: 2236-1170)

Os avanços da pecuária nacional são podem ser bastante visíveis, de forma que, ocupando exatamente a mesma área, o rebanho bovino brasileiro poderia dobrar, com a adoção de ferramentas simples de manejo e tecnologia. A década de 2000, a exemplo disso, foi marcada pela consolidação do Brasil como potência na produção e exportação de carne bovina, como segue a Figura 1, que mostra a evolução do volume de carne exportada em relação aos anos.

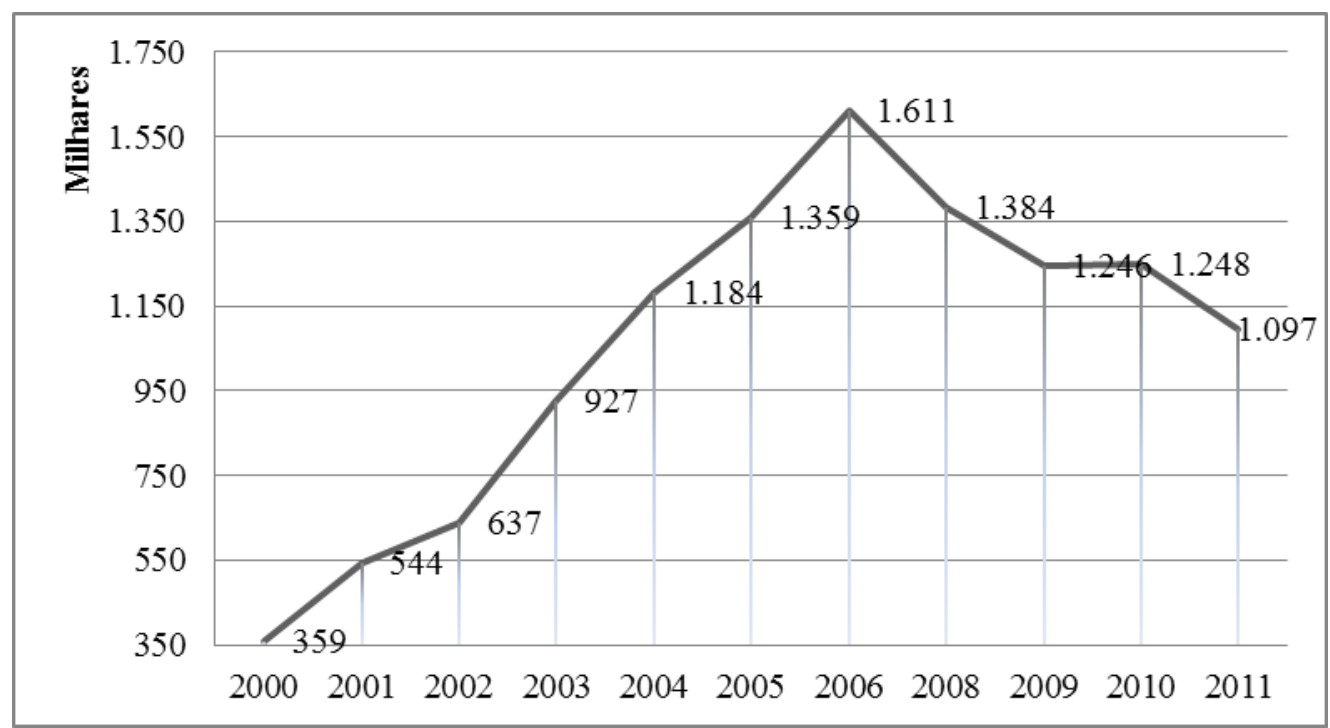

Figura 1. Exportações de carne bovina brasileira em milhares - 2000 a 2011

Fonte: Elaborado pelos autores com base de dados ABIEC (2012).

Ao analisar a Figura 1 nota-se que entre 2000 e $2006^{2}$ o Brasil apresentou um volume de carne exportada em evolução. Em dados mais precisos, de 2000 a 2006 o volume expandiu com crescimento de 77,26\%. Em contrapartida, a partir de 2008 o volume decresceu em 46,76\% até 2011. Há nitidamente um crescimento seguido de uma involução. O mercado como um todo se mostrou inconstante ao longo do período de análise, pois o único momento que apresentou constância foi entre os anos 2009 e 2010.

Machado \& Amin (2005) afirmam que o rebanho bovino brasileiro cresceu muito no início da década de 2000 em resposta aos estímulos da demanda externa e que, por conta disso, a pecuária de corte vem sofrendo profundas transformações desde meados da década de noventa. A disponibilidade de terras a baixo custo permitiu expandir a produção, para atender a demanda mundial crescente pelo produto brasileiro. Isso traz ao Brasil vantagem perante concorrentes como Austrália e Estados Unidos que possuem elevados custos em relação à atividade pecuária. 0 crescimento das exportações de carne exigiu que os frigoríficos se modernizassem, tendo em vista os rígidos padrões internacionais de controle de qualidade.

A ocorrência da vaca louca, simultaneamente, em vários países da União Europeia e da febre aftosa na Argentina em 2001, favoreceu o crescimento das exportações brasileiras de carne bovina. Assim, o Brasil passou a suprir os mercados atendidos por esses ofertantes devido às

\footnotetext{
${ }^{2}$ No ano de 2007 a ABIEC não disponibilizou em seu banco de dados informações referentes à exportações de carne bovina brasileira.
} 


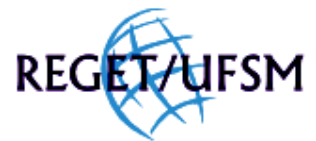

SANGUINET et all , v(11), no 11, p. 2389-2398, JUN, 2013.

Rev. Elet. em Gestão, Educação e Tecnologia Ambiental (e-ISSN: 2236-1170)

melhores condições sanitárias. O controle da febre aftosa foi uma condição básica para que o país pudesse vender carne in natura para o mercado externo, uma vez trouxe de volta a confiança do consumidor estrangeiro na qualidade do produto. Devido à vacinação contra a aftosa realizada de forma regular e abrangente, a partir da década de 1990, o Brasil foi considerado pela World Organization for Aninal Health (OIE) como área livre nos circuitos pecuários sul, leste e centrooeste.

O período em estudo revela que o mercado consumidor é volátil, com mostra a Figura 2.

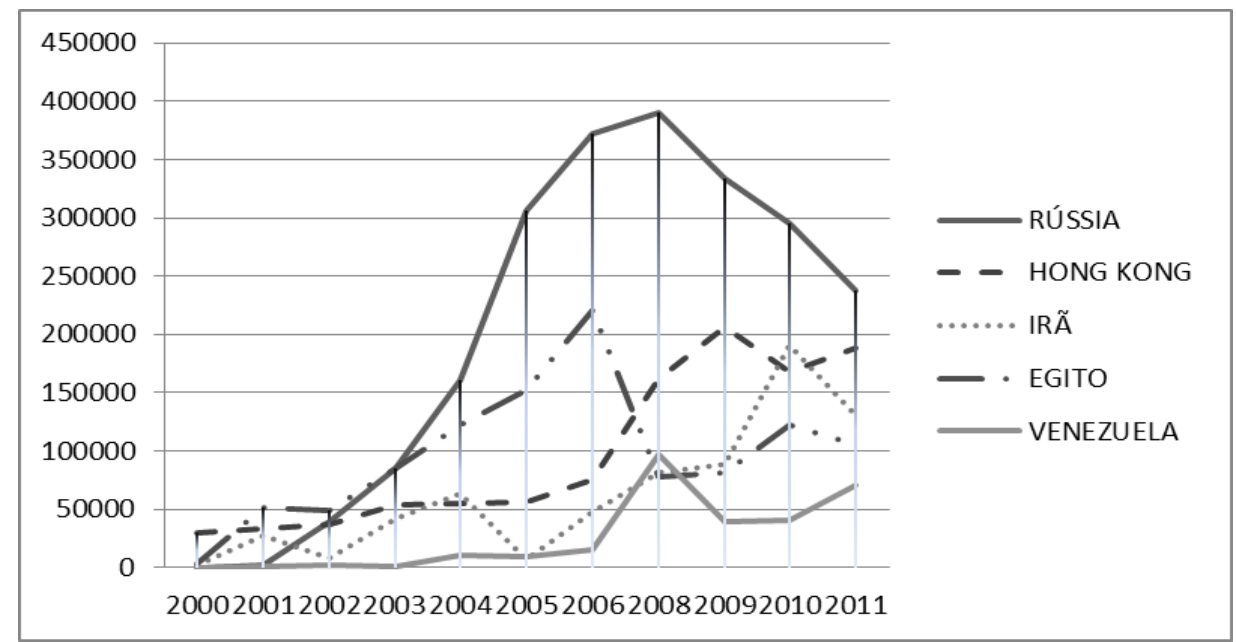

Figura 2. Variação das exportações para os cinco principais destinos da carne bovina brasileira em 2011 Fonte: Elaborado pelos autores com base de dados ABIEC (2012).

Apesar da inconstância, em termos de posição do ranking dos destinos da carne bovina brasileira, Rússia, Hong Kong, Irã, Egito e Venezuela se mostram como os principais compradores do produto brasileiro. Para Silva (2010) os problemas sanitários que ocorreram nos rebanhos bovinos de grandes potenciais exportadores, como União Europeia, Argentina, EUA, geraram um nicho de mercado para outros exportadores que, somou-se, ao processo de reorganização da cadeia produtiva de carne bovina, e a uma política cambial que passava a favorecer as exportações a partir de 1999. Esse conjunto de situações favoreceu o aumento da participação do Brasil no mercado internacional de carne.

As grandes flutuações nos níveis de compras demonstram que há certa instabilidade nas decisões de compra dos países consumidores. Nenhum dos países apresenta constância em termos de quantidade importada. Rússia, Egito, Hong Kong e Venezuela, no período compreendido entre 2000 e 2006 mostraram-se mercados em ascensão, pois houve aumento no volume importado pelos mesmos.

Apesar do grande potencial brasileiro na produção e venda de carne, Bellonia \& Silva (2007) salientam que muitos países, visando proteger seus mercados, vêm utilizando um arsenal de medidas conhecidas como barreiras não-tarifárias (BNTs), que acabam afetando a circulação de mercadorias e limitando o desempenho do setor exportador brasileiro. Essas barreiras são impostas por alguns países para estimular a produção e oferta interna e desaquecer as importações e, para o caso da carne bovina, podem ser impostas quotas de importação ou ainda a 


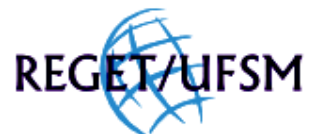

SANGUINET et all , v(11), no 11, p. 2389-2398, JUN, 2013.

Rev. Elet. em Gestão, Educação e Tecnologia Ambiental (e-ISSN: 2236-1170)

barreira pode ser definida devido a questões sanitárias e legislativas. As imposições quanto a questões sanitárias devem-se a preocupação dos governos quanto à segurança alimentar de seus consumidores e à saúde de seus animais, principalmente depois do surgimento de doenças como o mal da "vaca louca", febre aftosa e gripe aviária.

Os autores ainda afirmam que as exportações brasileiras de carnes são limitadas especialmente para países mais desenvolvidos como União Europeia e Estados Unidos. Nesses países, em geral, todas as linhas tarifárias e todas as exportações brasileiras de carnes estão sujeitas a algum tipo de barreira não-tarifária e, o nível de proteção do setor também é muito elevado. Os outros países apresentaram-se menos restritivos, principalmente com relação às questões sanitárias.

O maior importador de carne bovina brasileira, em quantidade é a Rússia. Devido aos embargos russos e chilenos decorrentes dos surtos da febre aftosa no Brasil, em 2006, ocorreu uma queda da sua quantidade importada. A partir de 2007, o preço médio da tonelada de carne elevou, mesmo com o cenário desfavorável, o surto de febre aftosa e desvalorização do dólar, colaborando para que houvesse uma queda nas vendas brasileiras.

Em resposta aos fatores internos e externos que corroboraram para que o Brasil se consolidasse no mercado internacional de carne bovina, a Tabela 1 a seguir mostra a variação do volume adquirido de carne dos 10 países que mais importaram o produto brasileiro no ano de 2011.

Tabela 1. Variação nas exportações de carne bovina (2000 - 2011)

\begin{tabular}{cc}
\hline PAÍS & VARIAÇÃO (\%) \\
\hline RÚSSIA & $100 \%$ \\
HONG KONG & $84 \%$ \\
IRÃ & $99 \%$ \\
EGITO & $96 \%$ \\
VENEZUELA & $100 \%$ \\
HOLANDA & $-27 \%$ \\
CHILE & $11 \%$ \\
ITALIA & $-9 \%$ \\
REINO UNIDO & $-90 \%$ \\
ESTADOS UNIDOS & $-190 \%$ \\
TOTAIS & $67 \%$ \\
\hline Fonte: Elaborado Pelos autores com base de dados ABIEC (2012).
\end{tabular}

Ao analisar da Tabela 1 verifica-se que a maioria dos consumidores aumentou o volume importado de carne no período compreendido de 2000 a 2011. Rússia e Venezuela aumentaram a participação em $100 \%$ e, em contrapartida, Reino Unido e Estados Unidos, mesmo estando entre os 10 principais compradores do produto no ano de 2011, apresentam queda de participação, com $-90 \%$ e $-190 \%$ respectivamente. 
REGEX

SANGUINET et all , v(11), no 11, p. 2389-2398, JUN, 2013.

Rev. Elet. em Gestão, Educação e Tecnologia Ambiental (e-ISSN: 2236-1170)

Quanto ao coeficiente de participação dos países da amostra, o grupo dos 10 países que mais importaram carne bovina brasileira no ano de 2011 apresentou variação quanto ao volume de compra do produto estudado. A Tabela 2 mostra o peso de participação das exportações de carne de 2000 a 2011.

Tabela 2. Participação no mercado exportador (\%)

\begin{tabular}{cccccccccccc}
\hline PAÍS & $\mathbf{2 0 0 0}$ & $\mathbf{2 0 0 1}$ & $\mathbf{2 0 0 2}$ & $\mathbf{2 0 0 3}$ & $\mathbf{2 0 0 4}$ & $\mathbf{2 0 0 5}$ & $\mathbf{2 0 0 6}$ & $\mathbf{2 0 0 8}$ & $\mathbf{2 0 0 9}$ & $\mathbf{2 0 1 0}$ & $\mathbf{2 0 1 1}$ \\
\hline RUSSIA & 0,00 & 0,42 & 6,17 & 9,22 & 13,56 & 22,53 & 23,08 & 28,21 & 26,80 & 23,68 & 21,65 \\
HONG KONG & 8,42 & 6,06 & 5,77 & 5,75 & 4,60 & 4,13 & 4,70 & 11,72 & 16,57 & 13,43 & 17,18 \\
IRÃ & 0,44 & 4,99 & 1,31 & 4,47 & 5,37 & 0,51 & 2,98 & 5,87 & 7,13 & 15,32 & 11,90 \\
EGITO & 1,06 & 9,41 & 7,74 & 9,13 & 10,36 & 11,23 & 13,71 & 5,62 & 6,52 & 9,84 & 9,63 \\
VENEZUELA & 0,01 & 0,17 & 0,28 & 0,10 & 0,93 & 0,67 & 0,97 & 7,00 & 3,21 & 3,21 & 6,46 \\
HOLANDA & 8,63 & 6,16 & 6,56 & 5,30 & 4,69 & 3,84 & 3,82 & 2,01 & 1,78 & 1,70 & 2,23 \\
CHILE & 8,85 & 10,43 & 11,93 & 11,11 & 8,88 & 4,94 & 0,29 & 0,29 & 0,48 & 1,71 & 3,24 \\
ITÁLIA & 7,54 & 5,31 & 5,34 & 4,75 & 4,28 & 4,26 & 3,75 & 1,69 & 1,99 & 2,11 & 2,26 \\
UK & 18,72 & 13,87 & 12,19 & 10,44 & 8,40 & 8,73 & 6,95 & 4,05 & 3,85 & 3,71 & 3,22 \\
USA & 10,62 & 7,05 & 7,40 & 5,95 & 4,74 & 3,87 & 3,74 & 3,88 & 3,61 & 1,28 & 1,20 \\
\hline \multicolumn{7}{c}{ Fonte: Elaborado pelos autores com base de dados ABIEC (2012). }
\end{tabular}

Com base nos dados da ABIEC, nota-se a que houve uma considerável variação no peso da participação de cada país da amostra quanto à compra de carne bovina brasileira. A Rússia, por exemplo, em 2000 participou de 0\% das exportações brasileiras e em 2008 compôs 28,20\% do total. O Irã, de 2000 a 2011 teve participação aumentada de 0,44\% para 11,89\% mostrando-se o terceiro maior importador do produto. Em contrapartida, os Estados Unidos em 2000 concentrava 10,62\% das importações do produto brasileira e em 2011 passa a representar 1,20\% tendo sua participação diminuída em 190\%. Outro país que reduziu a participação foi o UK que em 2000 detinha 18,72\% e em 2011 passa a 3,22\% do mercado, tendo sua redução de participação em 90\%.

Em relação aos índices de concentração para cada ano, o grupo CR10 apresentou variações ao decorrer dos anos, confirmando o fato de o mercado comprador da carne bovina do Brasil variar ao longo do tempo.

Tabela 3. Índices de Concentração - CR (\%)

\begin{tabular}{cccccccccccc}
\hline CR & $\mathbf{2 0 0 0}$ & $\mathbf{2 0 0 1}$ & $\mathbf{2 0 0 2}$ & $\mathbf{2 0 0 3}$ & $\mathbf{2 0 0 4}$ & $\mathbf{2 0 0 5}$ & $\mathbf{2 0 0 6}$ & $\mathbf{2 0 0 8}$ & $\mathbf{2 0 0 9}$ & $\mathbf{2 0 1 0}$ & $\mathbf{2 0 1 1}$ \\
\hline CR10 & 78,73 & 73,21 & 70,63 & 70,02 & 64,58 & 68,78 & 67,37 & 73,54 & 75,56 & 77,79 & 78,96 \\
CR9 & 74,94 & 68,25 & 67,84 & 64,27 & 62,67 & 65,68 & 64,17 & 71,85 & 73,78 & 75,58 & 77,77 \\
CR8 & 72,92 & 63,26 & 61,67 & 58,68 & 57,30 & 61,55 & 61,19 & 68,35 & 69,68 & 73,00 & 74,55 \\
CR7 & 64,50 & 59,21 & 58,24 & 55,89 & 54,92 & 59,40 & 59,76 & 66,34 & 67,69 & 71,31 & 72,28 \\
CR6 & 55,65 & 52,22 & 50,50 & 46,77 & 50,64 & 54,46 & 55,05 & 62,29 & 64,48 & 67,60 & 69,05 \\
CR5 & 50,58 & 42,81 & 43,43 & 37,55 & 40,28 & 50,20 & 51,31 & 56,67 & 60,63 & 64,38 & 66,82
\end{tabular}




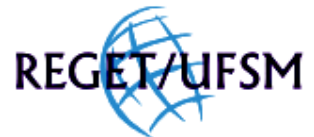

SANGUINET et all , v(11), no 11, p. 2389-2398, JUN, 2013.

Rev. Elet. em Gestão, Educação e Tecnologia Ambiental (e-ISSN: 2236-1170)

\begin{tabular}{cccccccccccc} 
CR4 & 45,50 & 37,50 & 38,08 & 32,80 & 35,54 & 46,33 & 47,56 & 52,79 & 54,11 & 62,27 & 60,36 \\
CR3 & 37,96 & 30,46 & 26,15 & 26,85 & 26,66 & 42,49 & 43,74 & 46,93 & 50,50 & 52,43 & 50,73 \\
\hline \multicolumn{1}{c}{ Fonte: Elaborado pelos autores com base de dados ABIEC (2012). }
\end{tabular}

A partir dos anos 2000, o Brasil se consolidou como grande exportador de carne bovina. Nota-se, pela Tabela 3, que este mercado é altamente concentrado, pois durante o período de análise, os 10 maiores compradores de carne bovina, juntos, representam mais de $60 \%$ dos consumidores totais de carne bovina. Ao longo do século 20, como já discutido, os países mostram-se inconstantes quanto ao volume de compra, mas o que caracteriza o setor comercial de carne bovina como altamente concentrado é que poucos clientes representam um percentual muito alto de aquisição do produto.

Alguns fatores colaboraram para que a concentração das vendas para um pequeno grupo se efetivasse. O Reino Unido, por exemplo, foi um dos países mais atingidos pela incidência de encefalopatia espongiforme bovina (BSE), o que provocou assim como em outros países com incidência da doença, na redução dos rebanhos, e consequentemente na oferta de carne bovina. Sacrifícios bovinos, suspensões das exportações por parte de alguns países, alegações de problemas sanitários são exemplos de fatores que nortearam mudanças drásticas no comércio do requerido bem em escala mundial. Silva (2010) destaca que esses acontecimentos tornam-se relevantes, pois os mesmos contribuíram para certas mudanças na dinâmica do comércio internacional de carne bovina, o qual implicou em transformações na dinâmica das exportações brasileiras.

Segundo Santos et al. (2007) o Brasil aproveitou a reestruturação da pecuária bovina na União Europeia, Estados Unidos e Canadá após o impacto causado pelo mal da vaca louca e pela febre aftosa, que resultaram em quase extermínio do rebanho bovino da União Europeia, bem como a crise econômico-financeira da Argentina, para ampliar sua participação nesse mercado. Estes fatores produziram, automaticamente, uma ampliação do excesso de demanda de carne bovina em relação à oferta no mercado internacional na década de 2000 e entre os países exportadores, um dos únicos em condições de atender a esse excesso de demanda era e o Brasil.

No ano de 2011, os países com maior representatividade nas exportações de carne bovina são Rússia, Hong Kong e Irã que juntos agregam um CR3 de 50,73\%. Desta forma, apenas 3 países são responsáveis por mais de $50 \%$ de todo um mercado consumidor, refletindo assim, os impactos que as mudanças do cenário comercial de carne bovina sofreu nos anos 2000 . Pode-se afirmar que há uma relação de dependência para com esses países devido ao peso de participação para esse setor, e salienta-se que a imposição de barreiras não-tarifárias mais rígidas podem prejudicar o cenário favorável do Brasil na comercialização do requerido bem. Assim, cabe às autoridades brasileiras ficarem atentas às políticas adotadas por esses governos, pressionando-os para que sejam mais transparentes nas negociações, a fim de evitar que medidas como a imposição dos diferentes tipos de barreiras não-tarifárias possam limitar o desempenho do setor exportador brasileiro (BELLONIA \& SILVA, 2007). 
Rev. Elet. em Gestão, Educação e Tecnologia Ambiental (e-ISSN: 2236-1170)

\section{CONCLUSÕES}

Verificou-se que houve um aumento do volume total de carne exportada de 2001 até 2006. Nesse período o volume exportado cresceu 77\%, porém, a partir de 2008 até 2011 apresentou uma queda de $46 \%$. Dos 10 países analisados pelo estudo, esse grupo de países representaram de 2001 a 2006 cerca de $65 \%$ de todas as exportações de carne bovina brasileira e a partir de 2008 até 2011, cerca de 75\%. Contudo, salienta-se que países como USA, Itália e Holanda apresentaram perda de participação em relação a outros como a Rússia e Venezuela.

O Brasil tornou-se um grande exportador de carne bovina durante os anos 2000, devido a mudanças internas que envolveram uma reorganização da cadeia produtiva e mudanças externas na redução da oferta de carne bovina e fatores externos que vieram a impactar a produção desse bem nem vários países. Assim, as relações comerciais brasileiras para o mercado de carne, também se transformou. Ao longo do período de análise houve muitas variações nos volumes comprados ano a ano confirmando o fato de haver certa volatilidade nessas relações de compra. As grandes flutuações nos níveis de compras demonstram que há certa instabilidade nas decisões de compra dos países consumidores.

O fato de os países analisados serem os principais mercados para a carne bovina do Brasil confirma-se pelo índice de concentração (CR). Os países analisados em 2000 mantinham um CR10 $=64,29 \%$ mostrando cerca constância até 2006. Em 2008 um salto é nítido, onde CR10 passa a ser de 70,33\% e mantem uma taxa de crescimento até o último ano da análise onde em 2011, CR10 das exportações totais de carne bovina brasileira é de $78,96 \%$. Ressalta-se que este mercado comprador vem se concentrando significativamente desde o ano de 2004, e, como é um mercado bastante volátil e inconstante por razões de barreiras tarifárias e também não tarifárias, a qualquer momento pode ocorrer um embargo por parte de algum destes países, e esta situação traria grandes problemas ao setor de carne bovina brasileira, principalmente se esta ação advier de algum país do CR3.

\section{REFERÊNCIAS BIBLIOGRÁFICAS}

ABIEC - ASSOCIAÇÃO BRASILEIRA DAS INDÚSTRIAS EXPORTADORAS DE CARNE. Estatísticas de Exportação, 2012. Disponível em: < http://www.abiec.com.br/texto.asp?id=31>.

Acesso em: jul. 2012.

BELLONIA, C. C. P; SILVA, O. M. Indicadores de barreiras não-tarifárias nas exportações de carnes do brasil. Revista Unioeste, v. 11, n. 1, 2007.

CURRY, B; GEORGE, D. Industrial Concentration: A Survey. The Journal of Industrial Economics, v. 31, n. 3, p. 203-255, 1983.

HALL, M.; TIDEMAN, N. Measures of Concentration. Journal of the American Statistical Association, v. 62, n. 317, p. 162-168, 1987.

HANNAH, L.; KAY, J. Concentration in Modern Industry. Macmillan, London, 1977.

KON, A. Economia industrial. São Paulo: Nobel, 1994, 212 p. 
REGEXfUFSM

SANGUINET et all , v(11), no 11, p. 2389-2398, JUN, 2013.

Rev. Elet. em Gestão, Educação e Tecnologia Ambiental (e-ISSN: 2236-1170)

MACHADO, L. V. N; AMIN, M. M. Análise da Posição Competitiva do Brasil no Mercado Internacional de Carne Bovina: Uma Aplicação do Método de Constant-Marke-Share (CMS) In: XLIII Congresso da Sociedade Brasileira de Economia e Sociologia Rural, 2005, Ribeirão Preto.

PEROBELLI, F. S. A cadeia da carne bovina no Brasil: uma análise de poder de mercado e teoria da informação. São Paulo: FGV, 2007. Tese de Doutorado (Doutorado em Economia de Empresas). Fundação Getúlio Vargas, 2007.

SANTOS, M. A. S. dos et al. Mercado e Dinâmica Local da Cadeia Produtiva da Pecuária de Corte na Região Norte. Belém: BASA, 2007. (Estudos Setoriais, 1).

SILVA, L. G. Pecuária e agroindústria de exportação na Amazônia: dinâmicas e perspectivas. Belém: UFP, 2010. Dissertação de Mestrado (Mestrado em Planejamento do Desenvolvimento). Universidade Federal do Pará, 2010. 